\title{
Surface energy and stiffness discrete gradients in additive manufactured scaffolds for osteochondral regeneration
}

Citation for published version (APA):

Di Luca, A., Longoni, A., Criscenti, G., Lorenzo-Moldero, I., Klein-Gunnewiek, M., Vancso, J., van Blitterswijk, C., Mota, C., \& Moroni, L. (2016). Surface energy and stiffness discrete gradients in additive manufactured scaffolds for osteochondral regeneration. Biofabrication, 8(1), [015014]. https://doi.org/10.1088/1758-5090/8/1/015014

Document status and date:

Published: 01/03/2016

DOI:

10.1088/1758-5090/8/1/015014

Document Version:

Publisher's PDF, also known as Version of record

Document license:

Taverne

Please check the document version of this publication:

- A submitted manuscript is the version of the article upon submission and before peer-review. There can be important differences between the submitted version and the official published version of record.

People interested in the research are advised to contact the author for the final version of the publication, or visit the DOI to the publisher's website.

- The final author version and the galley proof are versions of the publication after peer review.

- The final published version features the final layout of the paper including the volume, issue and page numbers.

Link to publication

\footnotetext{
General rights rights.

- You may freely distribute the URL identifying the publication in the public portal. please follow below link for the End User Agreement:

www.umlib.nl/taverne-license

Take down policy

If you believe that this document breaches copyright please contact us at:

repository@maastrichtuniversity.nl

providing details and we will investigate your claim.
}

Copyright and moral rights for the publications made accessible in the public portal are retained by the authors and/or other copyright owners and it is a condition of accessing publications that users recognise and abide by the legal requirements associated with these

- Users may download and print one copy of any publication from the public portal for the purpose of private study or research.

- You may not further distribute the material or use it for any profit-making activity or commercial gain

If the publication is distributed under the terms of Article $25 \mathrm{fa}$ of the Dutch Copyright Act, indicated by the "Taverne" license above, 
PAPER

\section{Surface energy and stiffness discrete gradients in additive manufactured scaffolds for osteochondral regeneration}

To cite this article: Andrea Di Luca et al 2016 Biofabrication 8015014

View the article online for updates and enhancements.
Related content

- Toward mimicking the bone structure:
$\frac{\text { design of novel hierarchical scaffolds with }}{\text { a tailored radial porosity gradient }}$
Andrea Di Luca, Alessia Longoni,
Giuseppe Criscenti et al.
- Triphasic scaffolds for the regeneration of
the bone-ligament interface
G Criscenti, A Longoni, A Di Luca et al.
- Additive manufactured polymeric 3D
scaffolds with tailored surface topography
influence mesenchymal stromal cells
activity
Sara C Neves, Carlos Mota, Alessia
Longoni et al.

\section{Recent citations}

\begin{tabular}{l} 
- Controlled drug release from electrospun \\
$\frac{\text { PCL non-woven scaffolds via multi- }}{\text { lavering and e-beam treatment }}$ \\
\hline Apollinariya A. Volokhova et al \\
- Scaffold-Dependent Mechanical and \\
$\frac{\text { Architectural Cues Guide Osteochondral }}{\text { Defect Healing in silico }}$ \\
Martina Tortorici et al \\
- Additive Manufactured, Highly Resilient. \\
Elastic and Biodegradable \\
$\frac{\text { Poly(ester)urethane Scaffolds with }}{\text { Chondroinductive Properties for Cartilage }}$ \\
$\frac{\text { Tissue Engineering }}{\text { Sandra Camarero-Espinosa et al }}$
\end{tabular}

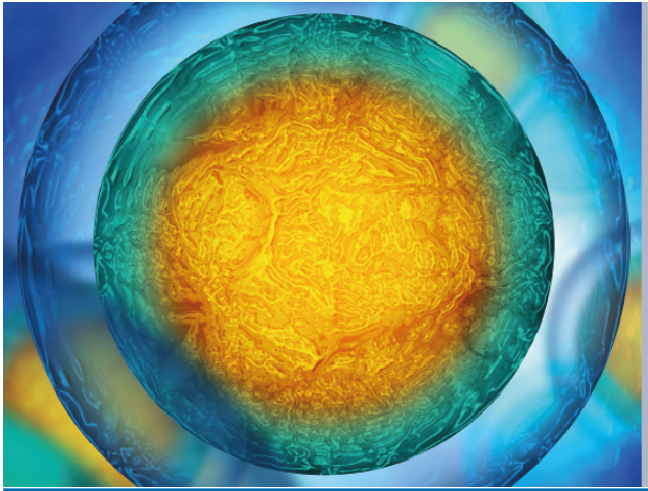

Biophysical Society $\quad$ IOP | ebookS

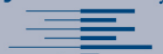

Your publishing choice in all areas of biophysics research.

Start exploring the collection-download the first chapter of every title for free. 


\title{
Biofabrication
}

\section{PAPER}

CrossMark

\section{RECEIVED}

16 November 2015

REVISED

21 December 2015

ACCEPTED FOR PUBLICATION

27 January 2016

PUBLISHED

22 February 2016

\section{Surface energy and stiffness discrete gradients in additive manufactured scaffolds for osteochondral regeneration}

\author{
Andrea Di Luca ${ }^{1}$, Alessia Longoni ${ }^{1}$, Giuseppe Criscenti ${ }^{1,2}$, Ivan Lorenzo-Moldero ${ }^{4}$, \\ Michel Klein-Gunnewiek ${ }^{3}$, Julius Vancso ${ }^{3}$, Clemens van Blitterswijk ${ }^{1,4}$, Carlos Mota $^{4}$ and Lorenzo Moroni ${ }^{1,4}$ \\ 1 University of Twente, Tissue Regeneration Department, Drienerlolaan 5,7522 NB, Enschede, The Netherlands \\ 2 Research center 'E. Piaggio', Faculty of Engineering, University of Pisa, Pisa, Italy \\ 3 University of Twente, Materials Science and Technology of Polymers group, Drienerlolaan 5, 7522 NB, Enschede, The Netherlands \\ 4 Maastricht University, MERLN Institute for Technology Inspired Regenerative Medicine, Complex Tissue Regeneration group, \\ Universiteitsingel 40, 6229ER Maastricht, The Netherlands \\ E-mail:1.moroni@maastrichtuniversity.nl
}

Keywords: additive manufacturing, gradients, 3D scaffolds, stem cells, biomaterials

Supplementary material for this article is available online

\begin{abstract}
Swift progress in biofabrication technologies has enabled unprecedented advances in the application of developmental biology design criteria in three-dimensional scaffolds for regenerative medicine. Considering that tissues and organs in the human body develop following specific physico-chemical gradients, in this study, we hypothesized that additive manufacturing (AM) technologies would significantly aid in the construction of 3D scaffolds encompassing such gradients. Specifically, we considered surface energy and stiffness gradients and analyzed their effect on adult bone marrow derived mesenchymal stem cell differentiation into skeletal lineages. Discrete step-wise macroscopic gradients were obtained by sequentially depositing different biodegradable biomaterials in the AM process, namely poly(lactic acid) (PLA), polycaprolactone (PCL), and poly(ethylene oxide terephthalate)/poly(butylene terephthalate) (PEOT/PBT) copolymers. At the bulk level, PEOT/PBT homogeneous scaffolds supported a higher alkaline phosphatase (ALP) activity compared to PCL, PLA, and gradient scaffolds, respectively. All homogeneous biomaterial scaffolds supported also a significantly higher amount of glycosaminoglycans (GAGs) production compared to discrete gradient scaffolds. Interestingly, the analysis of the different material compartments revealed a specific contribution of PCL, PLA, and PEOT/PBT to surface energy gradients. Whereas PEOT/PBT regions were associated to significantly higher ALP activity, PLA regions correlated with significantly higher GAG production. These results show that cell activity could be influenced by the specific spatial distribution of different biomaterial chemistries in a 3D scaffold and that engineering surface energy discrete gradients could be considered as an appealing criterion to design scaffolds for osteochondral regeneration.
\end{abstract}

\section{Introduction}

The osteochondral interface is the tissue allowing the transition from articular cartilage to the underneath trabecular bone. Gradients in structural and physicocemical properties such as stiffness, surface energy, and mineral content are important to determine a smooth transition [1-3] between skeletal tissues with great differences in structural and mechanical properties, resulting consequently in different functions. Nowadays, the most common pathological state of the osteochondral tissue is osteoarthritis. Currently available treatments in the clinics to regenerate osteochondral tissues, such as reparative surgery, allografts [4], autografts [5] and the implantation/ transplantation of autologous chondrocytes [6] are not yet completely successful. Besides limitations like the formation of fibrocartilage and lack of donor supply, these treatments inflict further tissue damage before any therapeutic effect can be achieved [6-8]. In the last couple of decades regenerative medicine has focused on possible alternatives to improve current therapies. In particular, the use of scaffolds to support and direct the growth of already differentiated cells or 
precursor cells, such as human mesenchymal stem or stromal cells (hMSCs), has gained a lot of interest. When successful, in fact, this strategy could lead to the implantation of instructive scaffolds only, thus limiting patient discomfort of multiple surgeries and associated healthcare costs. To serve this objective, scaffolds need to match functional requirements such as allowing nutrient in-flow and metabolites out-flow, facilitating cell migration and ECM formation, provide sufficient mechanical properties and adequate surface properties to orchestrate cell activity.

Different materials can be used for the production of scaffolds. In osteochondral tissue regeneration, polymers such as poly-lactic-acid (PLA) [9, 10], polycaprolactone (PCL) [11-13] and poly(ethylene oxide terephthalate)/poly(butylene terephthalate) PEOT/ PBT copolymers [14, 15] seem promising biomaterial candidates owing to their physico-chemical properties apted to skeletal applications. Furthermore, these polymers have been already approved from regulatory bodies for targeted applications in the orthopedic field, thus offering a more facile route towards clinical translation. Among scaffold production techniques, several have been applied for osteochondral regeneration such as gas foaming [16], salt leaching [17] and freeze-drying [18]. Yet, these techniques generate constructs that lack fundamental features such as pore interconnectivity, tailored and controlled pore size and shape, and resulting mechanical properties. In the past decade, additive manufacturing (AM) emerged as a powerful technology for scaffold design and fabrication, due to its ability to overcome these limitations. Via computer assisted design (CAD), AM allows to generate scaffolds with the desired shape, which is then converted in a program that is read by computer assisted manufacturing (CAM) software. The resulting scaffolds have a fully interconnected pore structure and features such as pore size, shape and fiber diameter can be varied during the entire manufacture process.

In recent years, hMSCs have found momentum in the proposed therapies for osteochondral regeneration. From a developmental point of view, both bone and cartilage originate from stem cells [19-21]. Several studies proved the ability of hMSCs to differentiate toward, among others, the osteogenic and chondrogenic lineage in vitro [22-25]. Their differentiation can be driven by different environmental cues such as nutrient and oxygen availability [26], surface and pore geometry [27, 28], presence of soluble factors [29-34] or substrate physico-chemical properties. In this respect, a number of studies demonstrated that the interaction between cells and substrates determines changes in the cytoskeleton which may trigger differentiation processes $[27,35,36]$. Among physico-chemical properties, the surface energy of a biomaterial substrate determines the amount of adsorbed protein [37] and, consequently, the anchor points that cells will encounter at the moment of attachment, eventually determining their final shape and spreading degree. Cell shape is known to regulate cell fate: hMSCs with rounded shape tends to differentiate toward the chondrogenic lineage [38] whereas a spread shape leads to an osteogenic differentiation [39]. Another cue that may trigger hMSCs differentiation via a cytoskeleton modification is the substrate stiffness, in a process known as mechanotransduction $[40,41]$. Cells cultured on a stiffer substrate will display a molecular expression pattern that leads to osteogenic differentiation [40], whereas cells grown on a softer substrate lead to differentiation toward a softer tissue lineage, such as chondrogenic differentiation [42].

Despite a number of studies showing the influence of surface energy and stiffness in two-dimensional substrates, limited work has been performed in threedimensional (3D) scaffolds [43, 44]. Here, we present a multi-material 3D scaffold fabricated by AM and based on three biodegradable polymers arranged in order to present a macroscopic step-wise discrete gradient either in surface energy or in stiffness. The influence of such 3D gradients on hMSCs differentiation toward the osteogenic and chondrogenic lineages was evaluated as potential scaffold design criteria to aid in steering stem cell activity for osteochondral tissue regeneration.

\section{Materials and methods}

\subsection{Scaffolds preparation}

Scaffolds were fabricated via AM with a Bioscaffolder (SysENG, Germany). Scaffolds made of PEOT/PBT, PCL, and PLA alone (used as controls) or in combination in the same scaffold construct were produced. PEOT/PBT copolymers belong to the group of block co-polymers characterized by an $a \mathrm{PEOT} b \mathrm{PBT} c$ nomenclature, where $a$ is the molecular weight of the starting PEG block and $b$ and $c$ are the PEOT/PBT ratio. Briefly, the polymers were placed in a stainless syringe and processed at $190^{\circ} \mathrm{C}(300$ PEOT55PBT45, PolyVation, The Netherlands), $100{ }^{\circ} \mathrm{C}$ (PCL, SigmaAldrich, USA), or $210^{\circ} \mathrm{C}$ (PLA, PLAtimer 228, PolyVation, The Netherlands). The molten polymers were extruded through a cartridge unit, by the application of a nitrogen flow with a pressure of 5 bars from a pressurized cap and an extrusion screw rotation of $200 \mathrm{rpm}$. During plotting, the needle diameter and layer thickness were kept constant at $250 \mu \mathrm{m}, 200 \mu \mathrm{m}$ and $180 \mathrm{~mm} \mathrm{~min}^{-1}$, respectively. The fiber spacing was kept constant at $750 \mu \mathrm{m}$. The translation speed of the plotting arm was $180 \mathrm{~mm} \mathrm{~min}^{-1}$ for PLA, $250 \mathrm{~mm} \mathrm{~min}^{-1}$ for PCL, and $550 \mathrm{~mm} \mathrm{~min}^{-1}$ for 300PEOT55PBT45. The plotted and tested samples were $6 \times 6 \times 3 \mathrm{~mm}$ blocks. The plotting process of the gradient scaffolds was based on the filling of three syringes, each with one polymer, heated to the right temperature. The CAD/CAM program was written 
for the manufacturing of six layers of each polymer, followed by changing of the syringe. The sequence of the surface energy (wettability) gradient was PLA300PEOT45 PBT55-PCL (WG), while the stiffness gradient followed the order PLA-PCL-300PEOT45 PBT55(SG).

\subsection{Polymer films and contact angle measurements}

In order to determine the surface energy, static contact angle measurements with water were performed by the sessile drop technique using an optical contact angle device equipped with an electronic syringe unit (OCA15, Dataphysics, Germany). To have a flat surface and to maintain the same temperature treatment as in AM processing, a film of each polymer was made via hot embossing. We reasoned that, being wettability a surface property related to how the material is processed, contact angle measurements on such hot embossed films could be equivalently representative of contact angle values of 3D scaffolds. Contact angle measurements on $3 \mathrm{D}$ scaffolds were otherwise challenging to test, due to the fact that water droplets were immediately entrapped in the scaffolds' pore network due to capillary forces. Specifically, PCL, 300PEOT55PBT45 and PLA discs of $500 \mu \mathrm{m}$ thickness were made by a hot-embossed compression moulding technique. Granules of each polymer were distributed inside circular punched moulds of stainless steel and placed between two silicon wafers functionalized with $1 \mathrm{H}, 1 \mathrm{H}, 2 \mathrm{H}, 2 \mathrm{H}$-perfluorodecyltrichorosilane (FDTS, Sigma-Aldrich). The wafer-mould-wafer stack was placed in the aperture of the temperature hydraulic press (Fortune Holland) at $80^{\circ} \mathrm{C}$ for PCL, $180{ }^{\circ} \mathrm{C}$ for 300PEOT55PBT45 and $230{ }^{\circ} \mathrm{C}$ for PLA and $10 \mathrm{bar}$. After $5 \mathrm{~min}$ the system was cooled to $60{ }^{\circ} \mathrm{C}$ and the pressure was released. The mould and wafer were manually separated to provide smooth discs. The discs were used for contact angle analysis, as above described.

\subsection{Mechanical testing at the macroscopic length scale}

The mechanical properties of the gradient scaffolds and the controls in wet and dry conditions were evaluated by uniaxial compression tests. For each configuration, six samples were analyzed. Samples were positioned in a standard compression block and aligned to the $500 \mathrm{~N}$ load cell of a Zwick materialstesting machine. To evaluate the influence of an aqueous environment and possible perfusion effects, tests were performed under two different environmental conditions: in a nitrogen atmosphere (dry condition) and in culture medium (alpha-MEM) at $37^{\circ} \mathrm{C}$ (wet condition). In the second case, the samples were left overnight in the medium at $37^{\circ} \mathrm{C}$ and a modified compression block was used to perform the test. All specimens were preloaded with $0.1 \mathrm{~N}$ and preconditioned by a series of ten cycles until a strain of
$5 \%$, with a strain rate of $1 \mathrm{~mm} \mathrm{~min}^{-1}$ to reduce the hysteresis. Subsequently, they were compressed at $1 \mathrm{~mm} \mathrm{~min}^{-1}$ until failure. A stress-strain curve representing the mechanical properties of the samples can be obtained from the cross-sectional area and the strain measurements. From the stress-strain curves, the following parameters were obtained: Young's modulus $(\mathrm{Pa})$, defined as the slope of the linear region of the stress-strain curve, ultimate stress $(\mathrm{Pa})$, ultimate strain (\%) and strain energy density $(\mathrm{Pa})$ at failure.

\subsection{Mechanical testing at the microscopic length scale}

Force measurements were performed on 3D scaffolds in air using a Dimension 3100 AFM equipped with a hybrid scanner and a NanoScope IVa controller (Veeco/Digital instruments (DI), Santa Barbara, CA, USA). Commercially available silicon cantilevers (PointProbe ${ }^{\circledR}$ Plus silicon probes, PPP-NCH, Nanosensors, Neuchatel, Switzerland) with a spring constant of around $42 \mathrm{Nm}^{-1}$ were used in the experiments. Force measurements were carried out with a $z$-ramp size of $2 \mu \mathrm{m}$, a scan rate of $1 \mathrm{~Hz}$, and a deflection trigger of $200 \mathrm{~nm}$. For every material around 1000 force curves were taken $(n=1000)$. The stiffness of the materials was defined as the slope of the approach curve from the point of contact up to an indentation force of $1 \mu \mathrm{N}$.

\subsection{Cell expansion and culture}

Pre-selected hMSCs (male, age 22) were retrieved from the Institute of Regenerative Medicine (Temple, Texas). Briefly, a bone marrow aspirate was drawn and mononuclear cells were separated using density centrifugation. The cells were plated to obtain adherent hMSCs, which were harvested when cells reached $60 \%-80 \%$ confluence. These were considered passage 0 (P0) cells. These P0 cells were expanded, harvested and frozen at passage 1 (P1) for distribution. Cells were grown in MSC proliferation medium, which contains minimal essential medium ( $\alpha$-MEM, Gibco, Breda, The Netherlands) supplemented with $10 \%$ fetal bovine serum (FBS, Lonza), $100 \mathrm{U} \mathrm{ml}^{-1}$ penicillin (Gibco, Breda, The Netherlands), $10 \mu \mathrm{g} \mathrm{ml}^{-1}$ streptomycin (Gibco, Breda, the Netherlands), $2 \mathrm{mM}$ L-glutamine (Gibco, Breda the Netherlands), $0.2 \mathrm{mM}$ L-ascorbic acid 2-phosphate magnesium salt (ASAp, Sigma-Aldrich, Zwijndrecht, The Netherlands) and $1 \mathrm{ng} \mathrm{ml}^{-1}$ of basic fibroblast growth factor-2 (bFGF-2, Fisher Scientific, Landsmeer, the Netherlands) at $37^{\circ} \mathrm{C}$ in a humid atmosphere with $5 \% \mathrm{CO}_{2}$. Cells were expanded up to approximately $80 \%$ confluency and either frozen for further use or seeded on the scaffolds.

\subsection{Cell seeding on scaffolds}

Briefly, after trypsinizaition with $0.25 \%$ trypsin (Life Technologies, Bleiswijk, the Netherlands), cells (passage 2-4) were counted using a Bückner chamber and 
re-suspended in proliferation media at a density of 500000 cells in $40 \mu \mathrm{l}$.

The day before seeding, scaffolds were disinfected in $70 \% \mathrm{EtOH}$ for 30 min under stirring, washed three times in phosphate buffered saline solution (PBS, Lonza, Breda, the Netherlands), and incubated overnight in cell proliferation media to allow protein adsorption on the scaffold's fibers. After protein adsorption, the $40 \mu \mathrm{l}$ of cell suspension were placed on the scaffold in a drop wise fashion to account for a cell seeding density of 500000 cells/scaffold. The seeded scaffolds were placed for $4 \mathrm{~h}$ in the incubator to allow cell adhesion before adding the cell culture media.

Cells were cultured on the gradient $(G)$ and nongradient (NG) scaffolds for seven days in proliferation media. At day 7, the proliferation media was changed and the cells within the scaffolds were cultured for another 7 and 28 days in basic media, mineralization media consisting of basic media supplemented with $10 \mathrm{nM}$ dexamethasone (Sigma-Aldrich, Zwijndrecht, the Netherlands) and $10 \mathrm{mM} \beta$-glycerol-phosphate (Sigma-Aldrich, Zwijndrecht, the Netherlands), and chondrogenic media consisting of DMEM supplemented with $50 \mathrm{mg} \mathrm{ml}^{-1}$ ITS-premix (Bexton Dickinson), $0.4 \mathrm{mM}$ Proline (Sigma-Aldrich, Zwijndrecht, the Netherlands), $50 \mathrm{mg} \mathrm{ml}^{-1}$ ascorbic acid (ASAp, Sigma-Aldrich, Zwijndrecht, the Netherlands), $100 \mathrm{mg} \mathrm{ml}^{-1}$ sodium pyruvate (Sigma-Aldrich, Zwijndrecht, the Netherlands), $100 \mathrm{U} \mathrm{ml}^{-1}$ penicillin (Life Technologies, Bleiswijk, the Netherlands), $10 \mu \mathrm{g} \mathrm{ml}^{-1}$ streptomycin (Life Technologies, Bleiswijk, the Netherlands), $10 \mathrm{ng} \mathrm{ml}^{-1}$ transforming growth factor $\beta 3$ (TGF- $\beta 3$ ) (Life Technologies, Bleiswijk, the Netherlands) and $10^{-7} \mathrm{M}$ dexamethasone (Sigma-Aldrich, Zwijndrecht, the Netherlands).

\subsection{Biochemical study}

\subsubsection{DNA analysis}

The cell number per scaffold was calculated from the $\mu$ g of DNA, obtained by a Cyquant DNA assay kit (Life Technologies, Bleiswijk, the Netherlands). Briefly, each scaffold was cut to improve lysis efficiency and freeze-thawed five times. After the freeze-thawing process, cells within the scaffolds were lysated by diluting the 20x lysis buffer provided with the kit using a saline buffer $(180 \mathrm{mM} \mathrm{NaCl}, 1 \mathrm{mM}$ EDTA in distilled water). After $1 \mathrm{~h}$ of lysis, samples were sonicated two times for $10 \mathrm{~s}$ using a Branson sonifier 250 (Emerson Industrial Automation, USA). DNA content was quantified with a CyQuant kit (Invitrogen, Breda, the Netherlands) according to manufacturer's protocol and fluorescence was measured at $480 \mathrm{~nm}$ using a spectrophotometer LS50B (Perkin Elmer, The Netherlands). DNA concentrations were calculated from a $\lambda$ DNA standard curve.

\subsubsection{Alkaline phosphatase (ALP) activity}

To evaluate hMSCs differentiation toward the osteogenic lineage, ALP content was measured using a CDP star kit (Roche, Woerden, the Netherlands). For this purpose, $10 \mu \mathrm{l}$ of sample was added to a well of a white 96-well plate and $40 \mu \mathrm{l}$ of substrate (disodium 2-chloro-5-(4-methoxyspiro [1,2-dioxetane-3,2'-(5'chloro)tricycle[3.3.1.13.7]decan]-4-yl)-1-phenyl phosphate) was added. After $15 \mathrm{~min}$ incubation, luminescence was read using a spectrophotometer LS50B (Perkin Elmer). ALP activity was corrected for DNA content.

\subsubsection{Glycosaminoglycan (GAG) amount}

To evaluate the differentiation toward the chondrogenic lineage, GAG amount was quantified using 1,9dimethyl methylene blue (DMMB) assay. Specifically, $25 \mu \mathrm{l}$ of sample were placed into a transparent flat bottom 96 well plate and $5 \mu \mathrm{l}$ of $2.3 \mathrm{M} \mathrm{NaCl}$ solution were added. Then, $150 \mu \mathrm{l}$ of DMMB solution were added and absorbance was read using a Multiscan Go (Thermo Scientific, USA) plate reader at a wavelength of $525 \mathrm{~nm}$. GAG content was quantified with a chondroitin sulphate standard curve and corrected for DNA content.

\subsection{Microscopy analysis-optical stereo and SEM}

G and NG scaffolds were analyzed by optical stereo microscopy and scanning electron microscopy (SEM, Philips-XL 30 ESEM-FEG). Directly after plotting, scaffolds were cut in half and pictures were taken with a stereological microscope. Afterwards, the samples were gold sputtered and analyzed by SEM. Scaffolds cultured in mineralization media for 3, 7 and 28 days were fixed using $10 \%$ formalin, dehydrated by an increased series of ethanol concentration (50-60 70-80-90-96-100\%) and cut in half. The final dehydration step was carried out via immersion in hexamethyldisilazane (Sigma Aldrich) and overnight evaporation. Dry scaffolds were mounted on SEM stubs, gold sputtered (Cressington sputter coater 108 auto), and analyzed using $10 \mathrm{kV}$ and a working distance of $25 \mathrm{~mm}$.

\subsection{Statistical analysis}

All quantitative data are expressed as mean \pm standard deviation (SD). Statistics were performed using IBM SPSS Statistics 20. A two-way statistical analysis of variance (ANOVA) with a significant $p$ level of 0.05 was used to determine differences between the groups and test conditions. Tukey's multiple comparisons test was used to perform post hoc analysis. Statistical significance between the control group and the experimental ones is indicated with $\left(^{*}\right)$ which represents a $p$ value $<0.05,\left({ }^{* *}\right)$ which represents a $p$-value $<0.01$, and $\left(^{* * *}\right)$ which represents a $p$-value $<0.001$. 

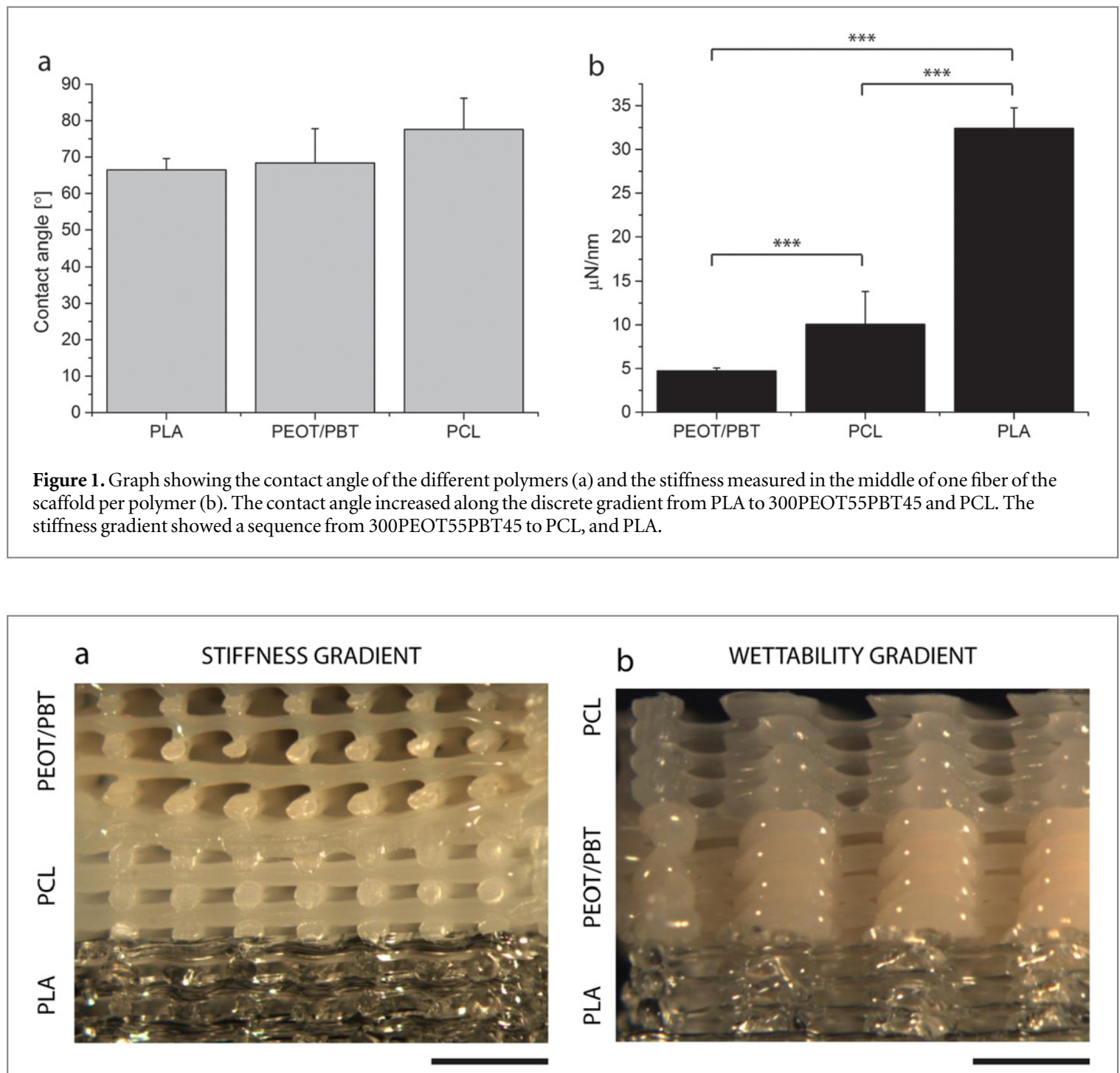

Figure 2. Steromicroscopical pictures of the cross section of the stiffness gradient scaffolds (a) and the wettability gradient scaffolds (b). Scale bar: $2 \mathrm{~cm}$.

\section{Results}

\subsection{Discrete gradient generation-contact angle measurements}

To determine the surface energy gradient, the contact angle of the single material was measured on polymer films. PLA showed a contact angle of $66.5^{\circ} \pm 3.1^{\circ}$, followed by PEOT/PBT $68.4^{\circ} \pm 9.4^{\circ}$ and PCL with the highest value $77.6^{\circ} \pm 8.6^{\circ}$. The chosen polymer sequence for the surface energy discrete gradient was PLA-PEOT/PBT-PCL (figure 1(a)).

\subsection{Gradient generation-stiffness}

The local surface mechanical properties of the 3 different polymers used to fabricate discrete gradient scaffolds were measured by AFM over 1000 different locations per scaffold region (figure 1(b)). PEOT/PBT displayed a stiffness of $4.73 \pm 0.35 \mu \mathrm{N} \mathrm{nm}^{-1}$, PCL of $10.07 \pm 3.74 \mu \mathrm{N} \mathrm{nm}^{-1}$, and PLA of $32.41 \pm$ $2.34 \mu \mathrm{N} \mathrm{nm}^{-1}$. The chosen sequence following the stiffness gradient was, therefore, PEOT/PBT-PCLPLA (figure 2).

The mechanical properties of the discrete gradient scaffolds and relative homogenous scaffold controls in wet and dry conditions were evaluated to further characterize the fabricated constructs at a structural level. Comparing the Young's modulus in dry conditions, the three materials showed a different mechanical behavior (figure 3). PEOT/PBT showed the lowest value $(17.07 \pm 0.99 \mathrm{MPa})$, followed by PCL $(50.62 \pm 1.38 \mathrm{MPa})$ and PLA $(107.86 \pm 9.8 \mathrm{MPa})$, respectively. The discrete gradient scaffolds displayed in dry and wet conditions a Young's modulus close to the most compliant PEOT/PBT scaffolds (figure 3). In addition, the WG scaffolds showed a higher ultimate stress both in dry and wet conditions compared to SG ones. However, an opposite trend was detected for the ultimate strain in dry and wet conditions. Finally, the SG scaffolds showed a higher strain energy density both in dry and wet conditions compared to the WG ones. 


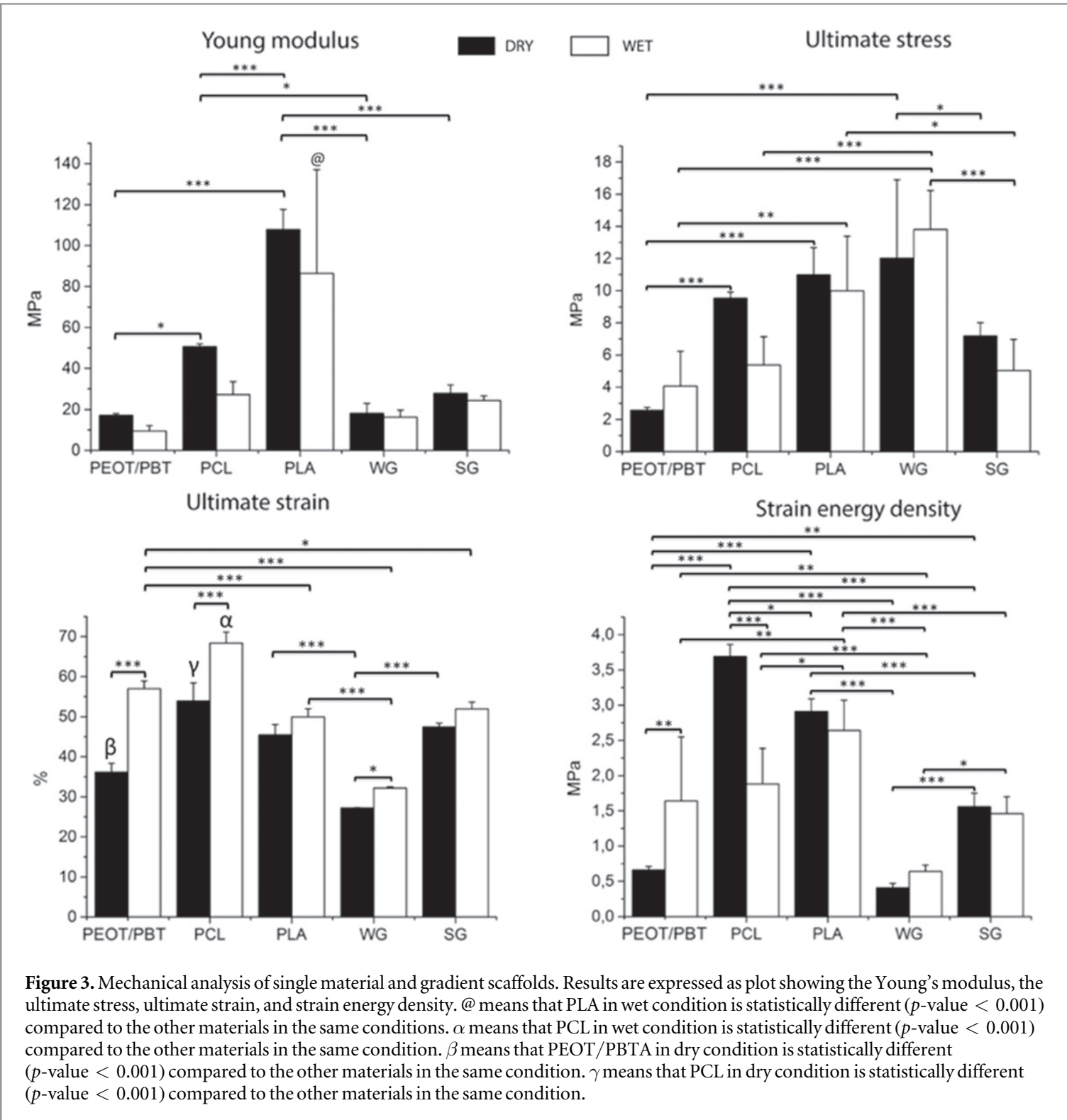

\subsection{Cell seeding efficiency and cell shape}

Cell seeding efficiency was not affected by the material or the type of gradient (supporting information, figure S1). All structures presented a cell seeding efficiency between $40 \%$ and $50 \%$, with a slight increase for the wettability gradient constructs. Cells displayed a different shape depending on the material they adhered on (figure 4). After 3 days of culture, hMSCs appeared homogeneously distributed in all the samples, their shape was elongated in PCL and PEOT/PBT, while on PLA their morphology looked more spread.

\subsection{Osteogenic and chondrogenic differentiation}

The ALP activity profile over time was the same for gradient and non-gradient scaffolds. ALP activity increased over time. After 28 days of culture in differentiation conditions, PEOT/PBT scaffolds outperformed the other constructs. When cultured under basic conditions, no major differences could be seen among the samples cultured for the same amount of time. Yet, an increase in ALP activity was observed after 28 days of culture in all the scaffolds compared to seven days of culture (Figure 5).

Similarly, the GAG amount produced by the cells within the samples cultured in basic medium did not show significant differences. When hMSCs were grown under basic conditions the single material constructs displayed a decreased (PCL, PLA) or a stable (PEOT/PBT) GAG amount. The GAG amount increased in the gradient scaffolds over time, yet not showing consistent differences with the single material scaffolds. Under chondrogenic conditions, the surface energy gradient (WG) outperformed the other constructs including the stiffness gradient at day 7 . This beneficial effect was lost after 28 days, in which the GAG content of the single material constructs was significantly higher with respect to the gradient samples (Figure 5). 


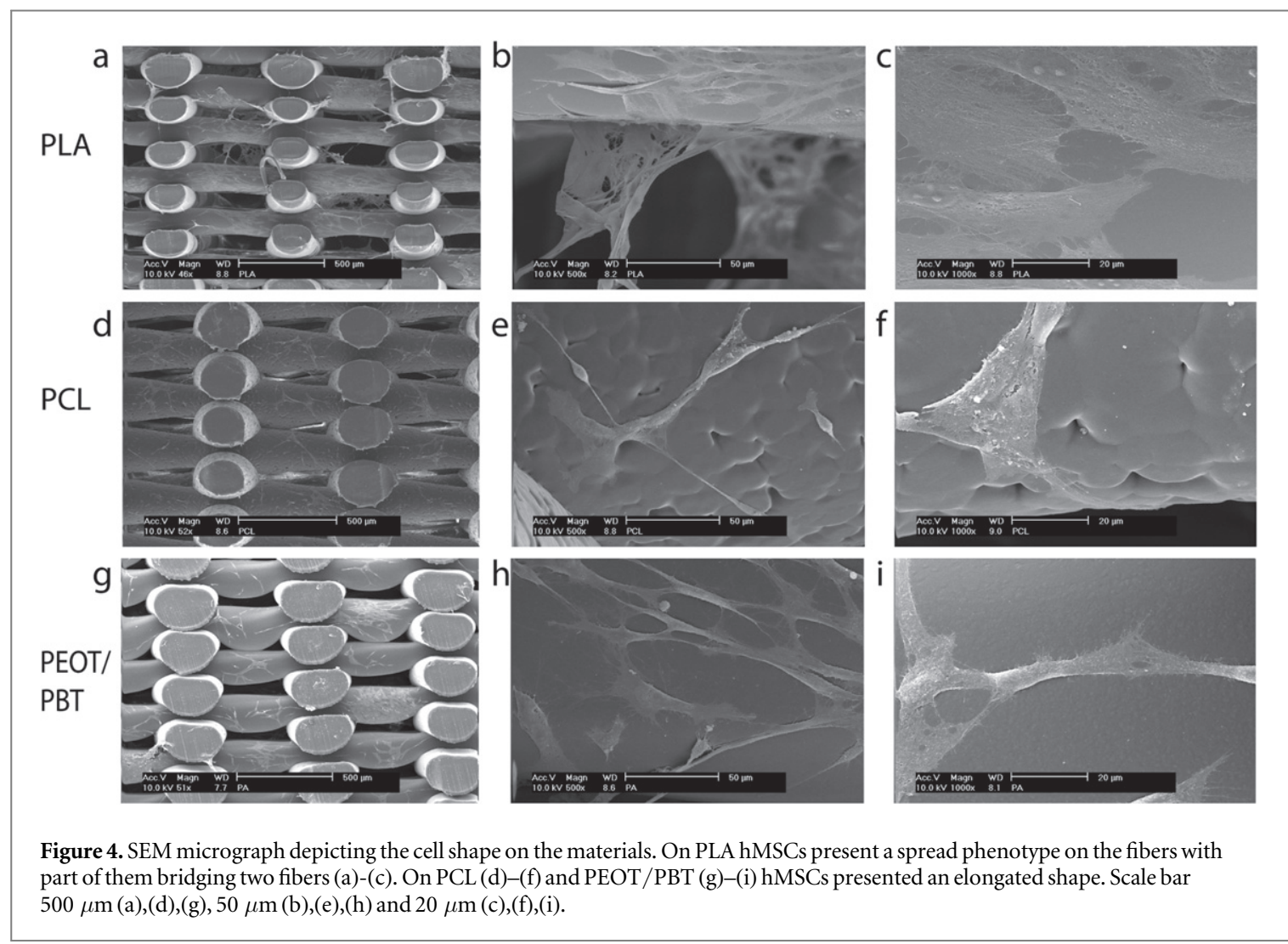

\subsection{Osteogenic and chondrogenic differentiation partition analysis}

To study whether the presence of these specific biomaterials in different regions of the gradient scaffolds had a net influence on cell differentiation, the scaffolds were segmented in the different material regions and analyzed. After seven days under mineralization conditions cells residing in the 300PEOT55PBT45 zone of the stiffness gradient showed the highest ALP activity level (figure 6) compared to the other regions. No other significant changes were, however, observed for the stiffness gradient constructs. Interestingly, in surface energy gradient scaffolds the 300PEOT55PBT45 region supported a significantly higher amount of produced GAGs compared the other material zones under chondrogenic conditions ay day 7 , whereas the PLA region outperformed the other materials at day 28 (figure 7). When cultured in mineralization medium, cells adhering on the PEOT/PBT regions showed significantly higher levels of ALP activity with respect to the levels displayed on PCL and PLA compartments.

\section{Discussion}

Several physico-chemical cues provided by biomaterials may act on the differentiation pattern of hMSCs. Among these, surface chemistry and mechanical properties are known to play an important role in two- dimensional substrates $[45,46]$. In the present study PCL, PLA and 300PEOT55PBT45 were plotted within the same scaffold in order to obtain a discrete gradient in surface energy and stiffness. The chosen polymers are FDA approved and widely used in osteochondral tissue engineering. PCL and PLA scaffolds alone or in combination with biological signals and cells have already shown promising results in vivo for bone regeneration [47, 48], whereas 300PEOT55PBT45 was studied for cartilage regeneration, reaching clinical evaluation $[49,50]$. The design of the surface energy gradient scaffolds was based on the analysis of the biomaterials wettability via water contact angle. The three materials chosen showed a similar surface energy, though a trend was observed with an increasing contact angle spanning from PLA to 300PEOT55PBT45 and PCL (figure 1(a)). In the design of the stiffness gradient scaffolds, differences in both bulk and surface mechanical properties were more pronounced while bulk mechanical properties were measured to characterize the structural mechanical behavior of the fabricated scaffolds, local surface mechanical properties were determined to decide the order of the three biomaterials in the final discrete gradient scaffolds. As expected, the local stiffness results revealed a greater stiffness of PLA followed by PCL and 300PEOT55PBT45. This was also confirmed at a scaffold macrostructural level by uniaxial compression, which becomes more relevant as the cells start to produce their ECM and occupy the pore volume. 


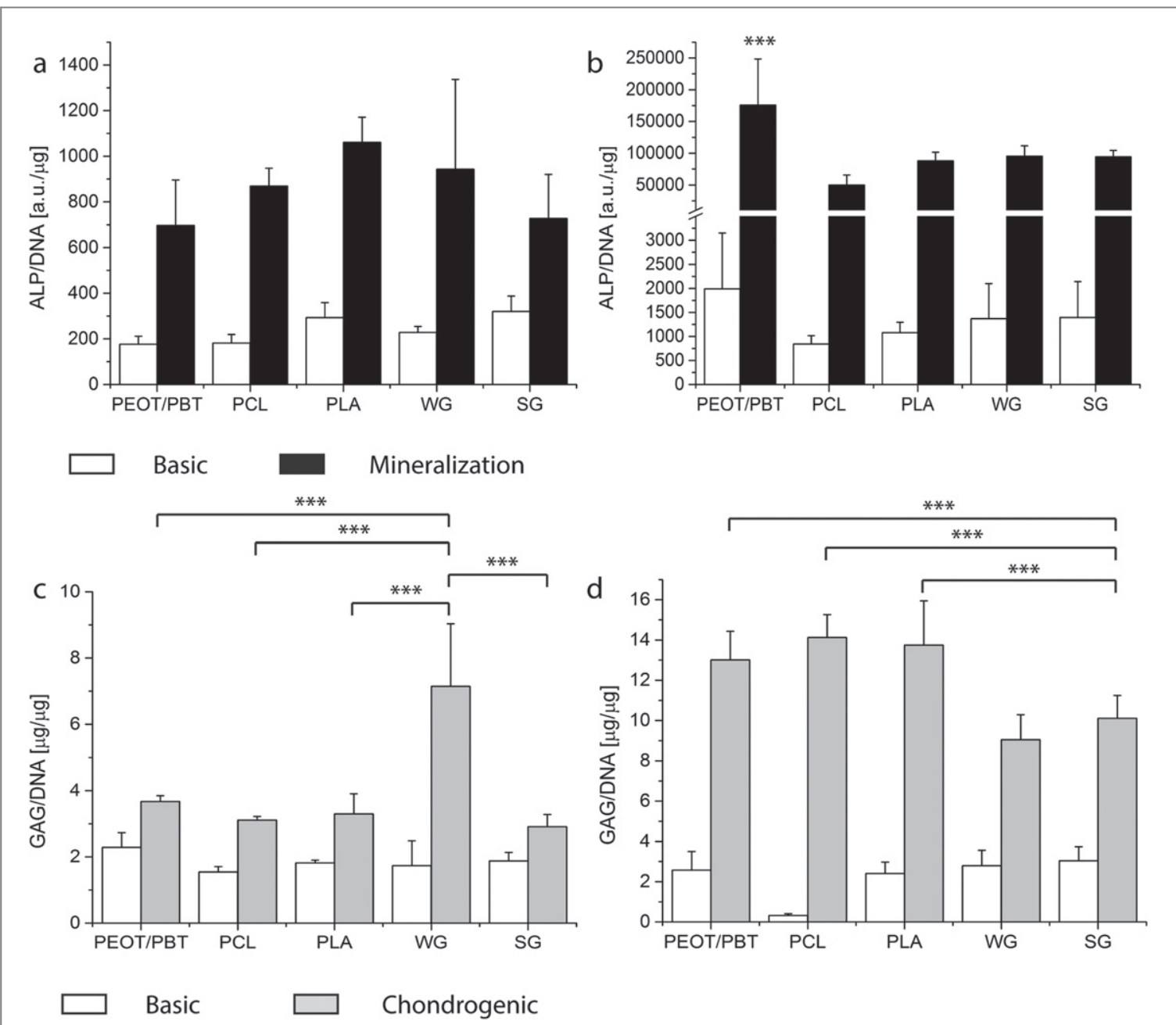

Figure 5. Graphs showing ALP activity (a),(b) and GAG amount (c),(d) in the full scaffolds at 7 (a),(c) and 28 (b),(d) days of culture. The ALP activity in all the samples was significantly increased over time. 300PEOT55PBT45 scaffolds showed the highest ALP activity after 28 days in differentiation media (b). At seven days under chondrogenic conditions WG scaffolds showed the highest GAG content (c). After 28 days under chondrogenic conditions the single material scaffolds outperformed the gradient scaffolds in GAG content $(\mathrm{d}) .{ }^{* * *}$ statistical significance, $p<0.001$.

The obtained mechanical properties adequately match the initial ones of the complex osteochondral structure [51, 52]. The use of the same geometry and scaffold layers for the scaffold macrostructure allowed obtaining a similar cross sectional area among the three different regions that promoted a discrete gradient of structural properties. During uniaxial compression test, the trimaterial scaffold regions are subjected to the same stress. For this reason, in first approximation, the mechanical behavior of the trimaterial scaffolds could be homogenized using a Reuss model. In this case, the mechanical response is described by equation (1):

$E_{\text {tot }}=$

$$
3 \cdot E_{\mathrm{PEOT} / \mathrm{PBT}} \cdot E_{\mathrm{PCL}} \cdot E_{\mathrm{PLA}}
$$

$\overline{E_{\mathrm{PEOT} / \mathrm{PBT}} \cdot E_{\mathrm{PCL}}+E_{\mathrm{PCL}} \cdot E_{\mathrm{PLA}}+E_{\mathrm{PEOT} / \mathrm{PBT}} \cdot E_{\mathrm{PLA}}}$

From equation (1), it is possible to conclude that the total Young's modulus is strongly dependent from the PEOT/PBT region that has the lowest Young's modulus.
In 2005, Yeung et al were among the first to show the correlation between substrate stiffness and cell shape [53]. The stiffness of the substrate is known to determine cytoskeleton modifications, in particular on the stress fibers. This modification results in a change of cell shape, which for stem cells is associated to a variation of their activity [54]. Cells on stiffer substrates showed a more spread phenotype compared to cells adhering on softer ones. In this study hMSCs showed spread morphology on all biomaterials, which might also explain the apparent lack of influence of the biomaterial stiffness in the evaluated range. Cells adhering on stiffer PLA showed a flatten morphology, which appeared more spindle-like on 300PEOT55PBT45 and on PCL (figure 4). The adsorption onto the material surface of serum and ECM proteins plays also an important role in cell adhesion and consequently cell morphology [55]. Protein adsorption is influenced by the material surface properties such as surface charge and chemistry, ultimately resulting in a different wettability. Tamada et al studied protein adsorption onto several polymeric 

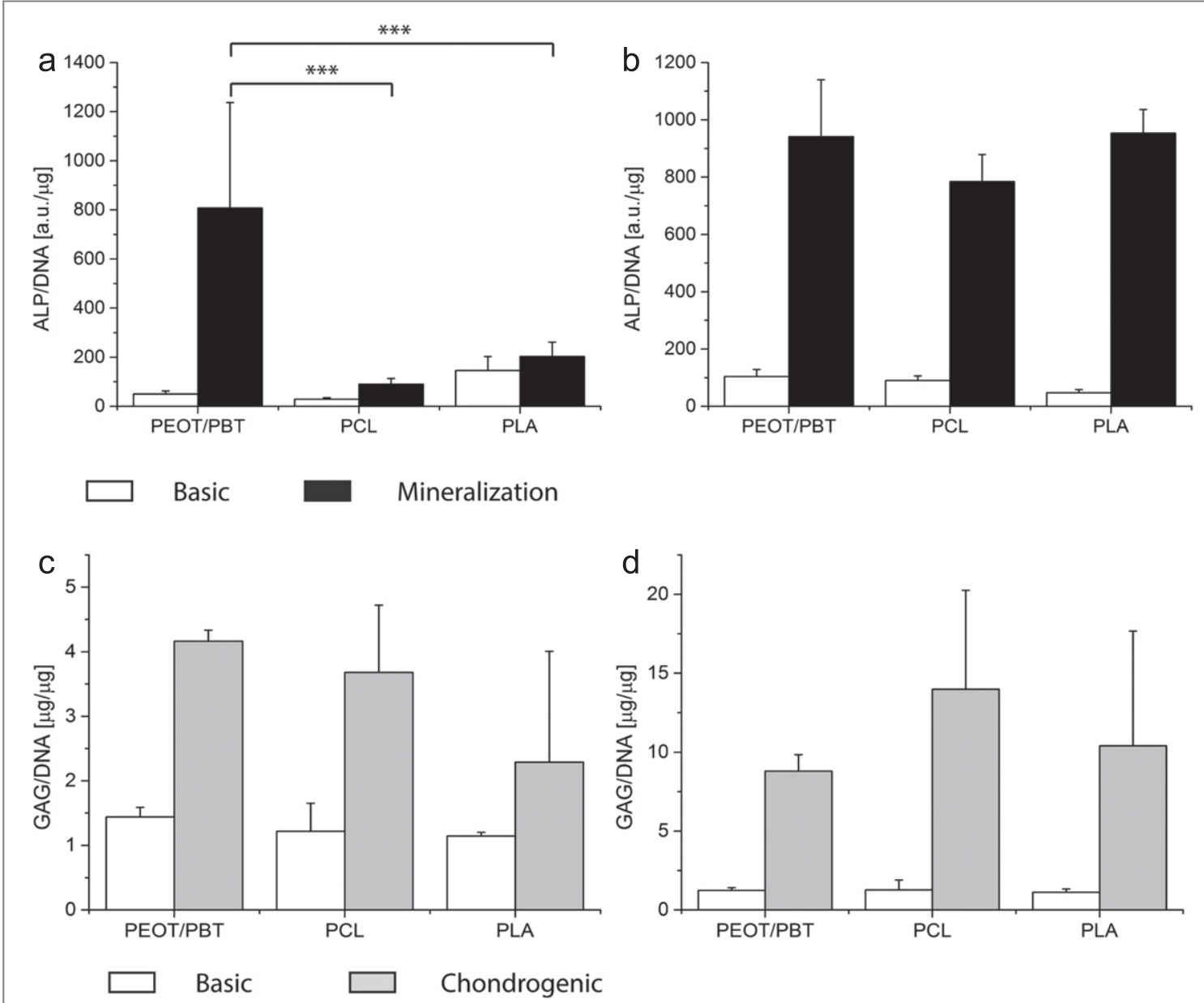

Figure 6. Plots showing the osteogenic and chondrogenic differentiation of hMSCs expressed as ALP activity (a),(b) and GAG amount (c),(d) at day 7 (a),(c) and day 28 (b),(d) per region of the stiffness gradients. At seven days, the 300PEOT55PBT45 showed a significantly higher ALP activity in the stiffness gradient. Under chondrogenic conditions no major differences could be seen in the stiffness gradient at 7 and 28 days.

surfaces and found that the maximum amount of protein adsorbed on culture substrates was on surfaces with water contact angles ranging between $60^{\circ}$ and $80^{\circ}$ [56]. The materials used in this study presented a contact angle in the range identified by Tamada (figure 1(a)). The contact angle was optimal for cell adhesion whereas the differences in surface stiffness determined a variation in cell morphology on the materials composing the discrete gradient scaffolds.

Although gradient scaffolds did not show any beneficial effect in the differentiation of hMSCs in absence of differentiation soluble factors over a culture period of four weeks, an effect of the different material regions in the gradient scaffolds was observed. Cell culture in mineralization medium is known to increase the osteogenic differentiation and the ALP activity levels are often considered as an early marker indicating osteogenic differentiation [57]. Only 300PEOT55PBT45 scaffolds supported an increased ALP activity compared to the gradient constructs and the other control scaffolds after 28 days under osteogenic conditions. WG scaffolds seemed to have an effect on GAG deposition after seven days under chondrogenic conditions. This effect was not visible anymore at 28 days, however, when the single-material scaffolds showed a greater amount of GAG compared to both WG and SG scaffolds. To elucidate the effect of each surface on hMSCs differentiation, a partition analysis was performed. According to previous studies, a trend in differentiation driven by the differences in polymer stiffness was expected. In 2011 Dupont et al described the role of YAP and TAZ, transducers of the Hippo signaling pathway, in the mechanotransduction and osteogenic differentiation of MSC adhering on stiffer substrates [58]. When growing on a stiff substrate, the YAP/TAZ localization was predominantly nuclear, whereas on softer substrate was cytoplasmic. The YAP/TAZ complex works as transcription factor and is involved in the osteogenic differentiation of hMSCs, by activating the Hippo pathway through modulating the cytoskeletal tension. On stiffer substrates hMSCs are more spread with a higher number of stress fibers, resulting in higher cytoskeletal tension that is expected to cause the translocation of YAP/TAZ in the nucleus and enhances the expression of osteogenic related genes. 


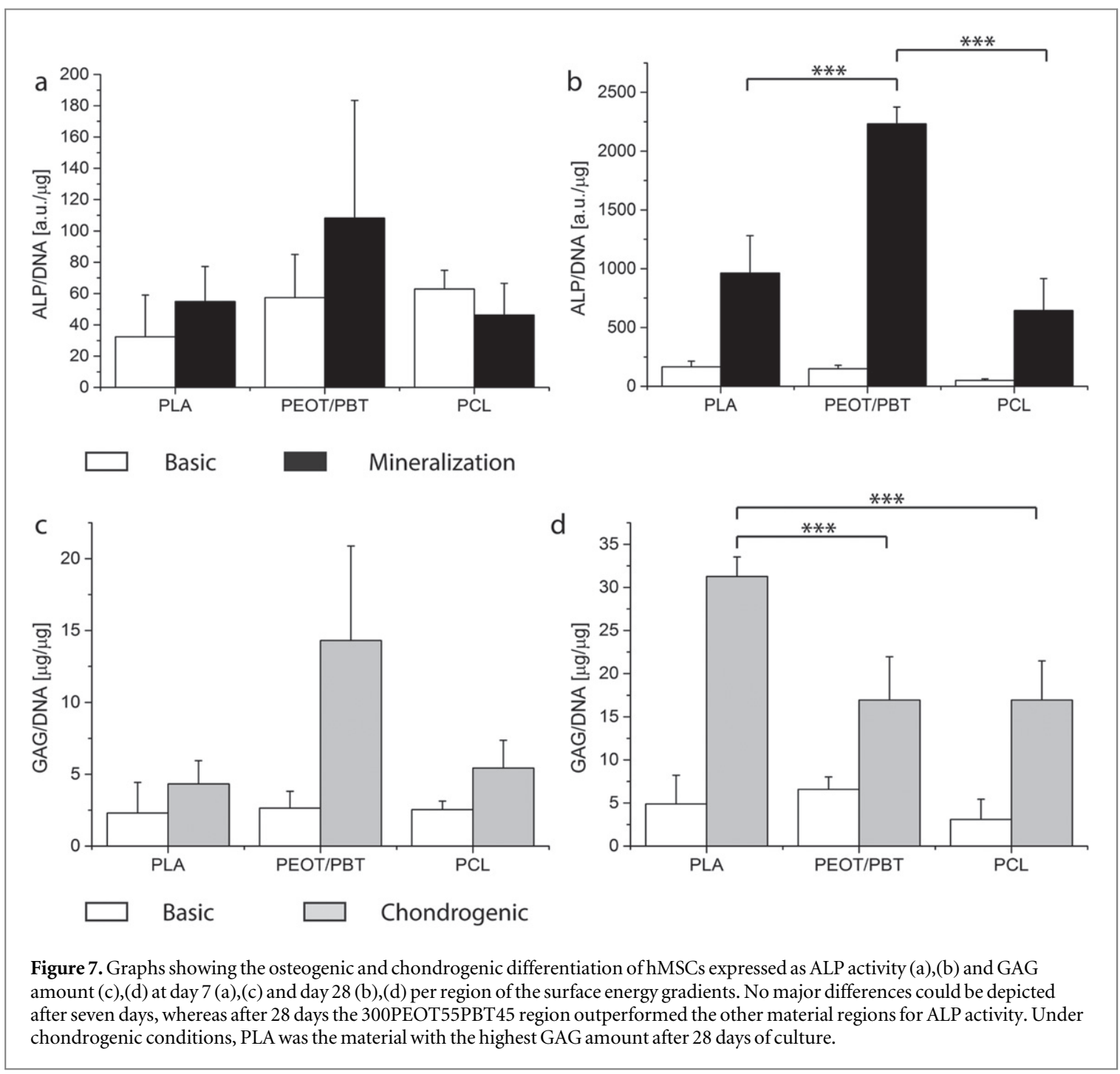

While it is known that the stiffness of cell culture substrates can influence stem cell fate in $2 \mathrm{D}$ on soft hydrogels varying in the range between $0,1-100 \mathrm{kPa}$ [45], limited knowledge is available in 3D and still circumscribed to hydrogels [43] where cells are embedded in a biomaterial. In case of stiffer scaffolds where cells are able to freely interact with the underneath biomaterial and to populate the pore network, much less is known. We have recently shown that hMSCs are able to sense the different stiffness of 3D scaffolds made of PCL with different molecular weight: lower molecular weight, associated to a lower stiffness in the $\mathrm{MPa}$ range, resulted in a higher hypertrophic chondrogenic differentiation [44]. In this study, in SG scaffolds the softer 300PEOT55PBT45 showed the highest ALP activity after seven days under osteogenic conditions. In WG scaffolds no major differences could be seen among the materials at seven days, but at 28 days 300PEOT55PBT45 again showed the highest ALP activity level with respect to the other materials. Under chondrogenic conditions the materials within the SG scaffolds did not show any major difference in GAG amount at 7 and 28 days. In WG scaffolds, however, the stiffer PLA region exhibited greater GAG amount with respect to the other materials after 28 days of chondrogenic culture. A possible explanation to the results may rely in the differentiation activation of soluble factors and mechanical cues. The differentiation media have the purpose of forcing the cell differentiation toward a certain lineage. Culture media and growth factors were refreshed every two days, affecting cell differentiation; hence cell shape and cytoskeleton organization. Plausibly, soluble factors have a stronger effect on hMSCs differentiation compared to mechanical cues in the stiffness range that was here considered. Additionally to soluble factors and mechanical properties, the chemistry of the different materials used and, in the specific case of WG scaffolds the gradual surface energy variation in the constructs, may have played a role in steering ALP activity and GAG production.

Further studies are needed to better characterize the effect of graded substrate stiffness and surface energy on stem cell activity at a molecular level. From an engineering perspective, a more continuous gradient could be obtained by changing the biomaterial composition every layer or by feeding two or more compositions into the extrusion chamber of the $3 \mathrm{D}$ 
plotter with controlled and tailorable feeding rates. While the first option would be directly applicable to current AM technology, the second approach would require the design and fabrication of new plotter heads. From a biological perspective, a longer study in basic conditions with more intermediate time points may highlight the solely effect of the substrate on which hMSCs are growing on. Additionally the 'priming' of hMSCs on stiff polystyrene cell culture substrates, a needed step to expand cells and obtain a sufficient number before scaffold seeding, might be a critical factor. Yang et al in fact, proved that hMSCs have a so called 'mechanical memory' [59], since their culture for long period on stiff substrate may alter their differentiation ability hampering those lineages triggered by a soft substrate. Furthermore, in vivo studies will also be conducted in the future to confirm these findings in a more pre-clinical setting. Nonetheless, the possibility to fabricate 3D plotted scaffolds with multiple materials components and changing the sequence with which specific physico-chemical properties are presented to cells seems to be an exciting new strategy to engineer material gradients in scaffolds' design and may contribute to further steer tissue formation.

\section{Conclusion}

AM was successfully used to fabricate scaffolds displaying either a stiffness or a surface energy discrete gradient by depositing multiple biodegradable biomaterials in different sequential orders. While stiffness gradients didn't seem to affect the behavior of seeded hMSCs in the investigated range, surface energy gradients resulted in enhanced early osteogenic differentiation on PEOT/PBT copolymer regions and improved chondrogenic differentiation in PLA regions. The creation of scaffolds with built-in engineered physico-chemical gradients could therefore be an appealing novel strategy in the design of 3D scaffolds for tissue regeneration applications.

\section{Acknowledgments}

This project was funded by the Dutch Technology Foundation STW (Grant number 11135). This project/research has been also made possible with the support of the Dutch Province of Limburg. Some of the materials used in this work were provided by the Texas A\&M Health Science Center College of Medicine Institute for Regenerative Medicine at Scott \& White through a grant from NCRR of the NIH (Grant \#P40RR017447).

\section{References}

[1] Eyre D 2002 Collagen of articular cartilage Arthritis Res. 430-5
[2] Ferguson V L, Bushby A J and Boyde A 2003 Nanomechanical properties and mineral concentration in articular calcified cartilage and subchondral bone J. Anat. 203 191-202

[3] Grogan S P et al 2013 Zone-specific gene expression patterns in articular cartilage Arthritis Rheumatism 65 418-28

[4] Ghazavi M T, Pritzker K P, Davis A M and Gross A E 1997 Fresh osteochondral allografts for post-traumatic osteochondral defects of the knee J. Bone Joint Surg. 79-B 1008-13

[5] Muller S, Breederveld R S and Tuinebreijer W E 2010 Results of osteochondral autologous transplantation in the knee Open Orthopaedics J. 4 111-4

[6] Bhosale A M and Richardson J B 2008 Articular cartilage: structure, injuries and review of management Br. Med. Bull. 87 77-95

[7] Buckwalter J A, Mow V C and Ratcliffe A 1994 Restoration of injured or degenerated articular cartilage J. Am. Acad. Orthopaedic Surgeons 2 192-201

[8] Hunziker E B 2002 Articular cartilage repair: basic science and clinical progress. A review of the current status and prospects Osteoarthritis Cartilage 10 432-63

[9] Slivka M A, Leatherbury N C and Kieswetter K 2001 Niederauer GG. Porous, resorbable, fiber-reinforced scaffolds tailored for articular cartilage repair Tissue Eng. 7 767-80

[10] Heymer A, Bradica G, Eulert J and Noth U 2009 Multiphasic collagen fibre-PLA composites seeded with human mesenchymal stem cells for osteochondral defect repair: an in vitro study J. Tissue Eng. Regenerative Med. 3 389-97

[11] Zein I and D W H * Tan K C and Teoh S H 2001 Fused deposition modeling of novel scaffold architectures for tissue engineering applications Biomaterials 23 1169-85

[12] Ding C et al 2013 Regeneration of a goat femoral head using a tissue-specific, biphasic scaffold fabricated with CAD/CAM technology Biomaterials 34 6706-16

[13] Liu X, Liu S, Liu S and Cui W 2014 Evaluation of oriented electrospun fibers for periosteal flap regeneration in biomimetic triphasic osteochondral implant J. Biomed. Mater. Res. B: Appl. Biomater. 102 1407-14

[14] Claase M B, Olde Riekerink M B, de Bruijn J D, Grijpma D W, Engbers G H M and Feijen J 2002 Enhanced bone marrow stromal cell adhesion and growth on segmented poly(ether ester)s based on poly(ethylene oxide) and poly(butylene terephthalate) Biomacromolecules 4 57-63

[15] Woodfield Cavb T B F, De Wijn J, Sims T J, Hollander A P and Riesle J 2005 Polymer scaffolds fabricated with pore-size gradients as a model for studying the zonal organization within tissue-engineered cartilage constructs Tissue Eng. 11 1297-311

[16] Salerno A, Iannace S and Netti P A 2012 Graded biomimetic osteochondral scaffold prepared via $\mathrm{CO}_{2}$ foaming and micronized NaCl leaching Mater. Lett. 82 137-40

[17] Harris L D, B-S K and Mooney D J 1998 Open pore biodegradable matrices formed with gas foaming J. Biomed. Mater. Res. 42 396-402

[18] Levingstone T J, Matsiko A, Dickson G R, O’Brien F J and Gleeson J P 2014 A biomimetic multi-layered collagen-based scaffold for osteochondral repair Acta Biomater. 10 1996-2004

[19] DeLise A M, Fischer L and Tuan R S 2000 Cellular interactions and signaling in cartilage development Osteoarthritis Cartilage 8309-34

[20] de Crombrugghe B, Lefebvre V and Nakashima K 2001 Regulatory mechanisms in the pathways of cartilage and bone formation Curr. Opin. Cell Biol. $13721-8$

[21] Provot S and Schipani E 2005 Molecular mechanisms of endochondral bone development Biochem. Biophys. Res. Commun. 328 658-65

[22] Deans R J and Moseley A B 2000 Mesenchymal stem cells: biology and potential clinical uses Exp. Hematol. 28 875-84

[23] Abdallah B M and Kassem M 2008 Human mesenchymal stem cells: from basic biology to clinical applications Gene Therapy 15 109-16

[24] Johnson Ket al 2012 A stem cell-based approach to cartilage repair Science 336 717-21 
[25] Bara J J, Richards R G, Alini M and Stoddart M J 2014 Concise review: bone marrow-derived mesenchymal stem cells change phenotype following in vitro culture: implications for basic research and the clinic Stem Cells 32 1713-23

[26] Malladi P, Y X, Xu Y, Chiou M, Giaccia A J and Longaker M T 2006 Effect of reduced oxygen tension on chondrogenesis and osteogenesis in adipose-derived mesenchymal cells Am. J. Physiol. Cell Physiol. 290 1139-46

[27] Kilian K A, Bugarija B, Lahn B T and Mrksich M 2010 Geometric cues for directing the differentiation of mesenchymal stem cells Proc. Natl Acad. Sci. USA 107 4872-7

[28] Knychala J, Bouropoulos N, Catt C J, Katsamenis O L, Please C P and Sengers B G 2013 Pore geometry regulates early stage human bone marrow cell tissue formation and organisation Ann. Biomed. Eng. 41 917-30

[29] Lavery K, Swain P, Falb D and Alaoui-Ismaili M H 2008 BMP2/4 and BMP-6/7 differentially utilize cell surface receptors to induce osteoblastic differentiation of human bone marrowderived mesenchymal stem cells J. Biol. Chem. 283 20948-58

[30] Lu H et al 2012 Spatial immobilization of bone morphogenetic protein-4 in a collagen-PLGA hybrid scaffold for enhanced osteoinductivity Biomaterials 33 6140-6

[31] Re'em T, Witte F, Willbold E, Ruvinov E and Cohen S 2012 Simultaneous regeneration of articular cartilage and subchondral bone induced by spatially presented TGF-beta and BMP-4 in a bilayer affinity binding system Acta Biomater. 8 3283-93

[32] Nishimura R, Hata K, Matsubara T, Wakabayashi M and Yoneda T 2012 Regulation of bone and cartilage development by network between BMP signalling and transcription factors J. Biochem. 151 247-54

[33] Barry F, Boynton R E, Liu B and Murphy J M 2001 Chondrogenic differentiation of mesenchymal stem cells from bone marrow: differentiation-dependent gene expression of matrix components Exp. Cell Res. 268 189-200

[34] Chen J et al 2011 Simultaneous regeneration of articular cartilage and subchondral bone in vivo using MSCs induced by a spatially controlled gene delivery system in bilayered integrated scaffolds Biomaterials 32 4793-805

[35] McBeath R, Pirone D M, Nelson C M, Bhadriraju K and Chen C S 2004 Cell shape, cytoskeletal tension, and RhoA regulate stem cell lineage commitment Dev. Cell. 6483-95

[36] Even-Ram S, Artym V and Yamada K M 2006 Matrix control of stem cell fate Cell 126 645-7

[37] Wei J et al 2009 Influence of surface wettability on competitive protein adsorption and initial attachment of osteoblasts Biomed. Mater. 4045002

[38] Zanetti N C and Solursh M 1984 Induction of chondrogenesis in limb mesenchymal cultures by disruption of the actin cytoskeleton J. cell Biol. 99 115-23

[39] Guilak F, Cohen D M, Estes B T, Gimble J M, Liedtke W and Chen C S 2009 Control of stem cell fate by physical interactions with the extracellular matrix Cell Stem Cell 5 17-26

[40] Chatterjee Ket al 2010 The effect of 3D hydrogel scaffold modulus on osteoblast differentiation and mineralization revealed by combinatorial screening Biomaterials 31 5051-62

[41] Dupont S et al 2011 Role of YAP/TAZ in mechanotransduction Nature 474 179-83
[42] Park J S et al 2011 The effect of matrix stiffness on the differentiation of mesenchymal stem cells in response to TGFbeta Biomaterials 32 3921-30

[43] Huebsch N et al 2010 Harnessing traction-mediated manipulation of the cell/matrix interface to control stem-cell fate Nat. Mater. 9518-26

[44] Hendrikson W J, Rouwkema J, van Blitterswijk C A and Moroni L 2015 Influence of PCL molecular weight on mesenchymal stromal cell differentiation R. Soc. Chem. Adv. 5 54510-6

[45] Engler A J, Sen S, Sweeney H L and Discher D E 2006 Matrix elasticity directs stem cell lineage specification Cell 126 677-89

[46] McBeath R, Pirone D M, Nelson C M, Bhadriraju K and Chen C S 2004 Cell shape, cytoskeletal tension, and RhoA regulate stem cell lineage commitment Dev. Cell 6 483-95

[47] Reichert J C et al 2012 A tissue engineering solution for segmental defect regeneration in load-bearing long bones Sci. Transl. Med. 4 141ra93

[48] Ge Z, Tian X, Heng B C, Fan V, Yeo J F and Cao T 2009 Histological evaluation of osteogenesis of 3D-printed polylactic-co-glycolic acid (PLGA) scaffolds in a rabbit model Biomed. Mater. 4021001

[49] Bartha L et al 2013 A clinical feasibility study to evaluate the safety and efficacy of PEOT/PBT implants for human donor site filling during mosaicplasty Eur. J. Orthopaedic Surg. Traumatol.: Orthopedie Traumatol. 23 81-91

[50] Emans P Jet al 2013 Tissue-engineered constructs: the effect of scaffold architecture in osteochondral repair J. Tissue Eng. Regener. Med. 7 751-6

[51] Athanasiou K A, Zhu C, Lanctot D R, Agrawal C M and Wang X 2000 Fundamentals of biomechanics in tissue engineering of bone Tissue Eng. 6361-81

[52] Mow V C, Ratcliffe A, Rosenwasser M P and Buckwalter J A 1991 Experimental studies on repair of large osteochondral defects at a high weight bearing area of the knee joint: a tissue engineering study J. Biomech. Eng. 113 198-207

[53] Yeung T et al 2005 Effects of substrate stiffness on cell morphology, cytoskeletal structure, and adhesion Cell Motil. Cytoskeleton 60 24-34

[54] Zemel A, Rehfeldt F, Brown A E, Discher D E and Safran S A 2010 Cell shape, spreading symmetry and the polarization of stress-fibers in cells J. Phys. Condens. Matter: Inst. Phys. J. 22 194110

[55] Brynda E, Hlady V and Andrade J D 1990 Protein packing in adsorbed layers studied by excitation-energy transfer $J$. Colloid Interface Sci. 139374-80

[56] Tamada Y and Ikada Y 1993 Effect of preadsorbed proteins on cell adhesion to polymer surfaces J. Colloid Interface Sci. 155 334-9

[57] Langenbach F and Handschel J 2013 Effects of dexamethasone, ascorbic acid and beta-glycerophosphate on the osteogenic differentiation of stem cells in vitro Stem Cell Res. Therapy 4117

[58] MacQueen L, Sun Y and Simmons C A 2013 Mesenchymal stem cell mechanobiology and emerging experimental platforms J. R. Soc. Interface 1020130179

[59] Yang C, Tibbitt M W, Basta L and Anseth K S 2014 Mechanical memory and dosing influence stem cell fate Nat. Mater. 13 $645-52$ 